\title{
Connaught Tunnel, UK: condition and repairs
}

David Wilde BSC, CEng, MICE, MIStructE

Senior Engineer, Arup-Atkins, London, UK (david.wilde@arup.com)

The aims of this paper are to record how the Connaught Tunnel was surveyed, assessed and repaired by Crossrail for use for the new Elizabeth line in London, UK. The challenges and changes involved with implementing the repairs required to bring an example of Victorian engineering back into use again were based on Network Rail guidance and other current practice. The repairs will reduce future maintenance requirements, which will benefit railway operations in the future. Groundwater leakage remains within the tunnel as the cost of rectifying the leaks, if successful, would have been prohibitive. Prior to the Crossrail Act of 2008, consideration was given to the wholelife costing of reusing the tunnel as opposed to boring new tunnels, and the cost of new tunnels was considered to be higher than the costs of repairs, maintenance and ongoing drainage requirements to reuse the existing tunnel.

\section{Introduction}

Current knowledge of causes of defects in railway tunnels and the application of appropriate repairs is provided in Network Rail's Technical User Manual for the Application of Standard Tunnel Repairs (NR/CIV/TUM/520) (Network Rail, 2009a). This is complemented by Construction Industry Research and Information Association's (Ciria) report C671, Tunnels: Inspection, Assessment and Maintenance (McKibbins et al., 2010). Brickwork repair details for tunnels are provided in a series of standard Network Rail drawings, NR/CIV/SD/520 to NR/CIV/SD/541, Tunnel Lining Maintenance Repair (Network Rail, 2009b). The aims of this paper are to record how the Connaught Tunnel was surveyed, assessed and repaired together with the challenges and changes involved with implementing the repairs required to bring an example of Victorian engineering back into use again. The location of the tunnel is shown in Figure 1.

\subsection{History of the railway}

The Connaught Tunnel, designed by Sir Alexander Meadows Rendel, son of the founder of the eponymous firm of engineers, is located in London's historical Docklands, UK, to the east of the city and is beneath the navigation channel, also known as the 'Dock Passage', between the Royal Victoria and Royal Albert Docks. The rail tunnel was built in 1878 by cut-and-cover methods and is formed of brickwork arches on beds of mass concrete (Anon, 1878). Some of the original drawings of the tunnel are archived at the London Docklands Museum. The longitudinal profile of the tunnel and approach cuttings is shown in Figure 2. The dock passage was deepened in 1933-1937, to accommodate ships of greater draught (Liddell, 1939). This involved the strengthening of the existing twin brickwork tunnels under the passage with cast-steel linings and the removal of brickwork above the tunnels. The passage was also widened to accommodate shipping of a $24 \mathrm{~m}$ beam, which involved the partial removal and replacement of the south dock wall using a combination of sheet piles and a relieving platform, with the works being completed in 1959 (Glover et al., 1959).

Goods services were withdrawn from the railway in 1970, and the Royal Docks closed to commercial traffic in the 1980s. With the expansion of the Docklands Light Railway and the opening of a dedicated station for the London City airport in 2005, passenger services on the North London line ceased in 2006.

The Crossrail Act of 2008 incorporated the tunnel into the southeast branch of the new line between the Custom House station and North Woolwich Portal. Network Rail remained responsible for maintaining the tunnel until the Crossrail programme of works started in 2012. The civil works were completed in 2015. The tunnel is not on the National Heritage List for England.

\subsection{Description of the structure}

The tunnel consists of a number of distinct structures as shown in Figure 2.

In order to accommodate the new railway and the space proofing for overhead line equipment and other line-wide services, the twin tunnels between the single-tunnel bellmouths were replaced with a new reinforced-concrete box structure. The existing singletunnel invert structure was replaced with a new reinforcedconcrete invert over an approximate total length of $110 \mathrm{~m}$, and additional concrete invert slabs were constructed in the approach ramps over an approximate total length of $160 \mathrm{~m}$ where the track ballast was previously supported by the ground (Wilde and Craft, 2015 , 2016). The remainder of the structure was original construction and was retained.

The approach ramp retaining walls shown in Figure 3 are of mass-concrete construction built without movement joints. The walls at the top of the ramps are gravity structures and embedded approximately $3 \mathrm{~m}$ below track level. A concave mass-concrete invert exists further down the ramps, and this extends as far as the single-tunnel sections. The deeper sections of the cuttings are propped by high-level mass-concrete arches. These concrete arches were formed using brickwork centring. The shallower sections of the cuttings consisted of gravity-retaining walls, and the original ballasted trackbed had been constructed primarily on River Terrace Deposits. Groundwater emanating from these deposits was directed towards the tunnel nadir. The new reinforced concrete contained weepholes in a central channel to 
Engineering History and Heritage

Volume 172 Issue EH2
Connaught Tunnel, UK: condition

and repairs

Wilde

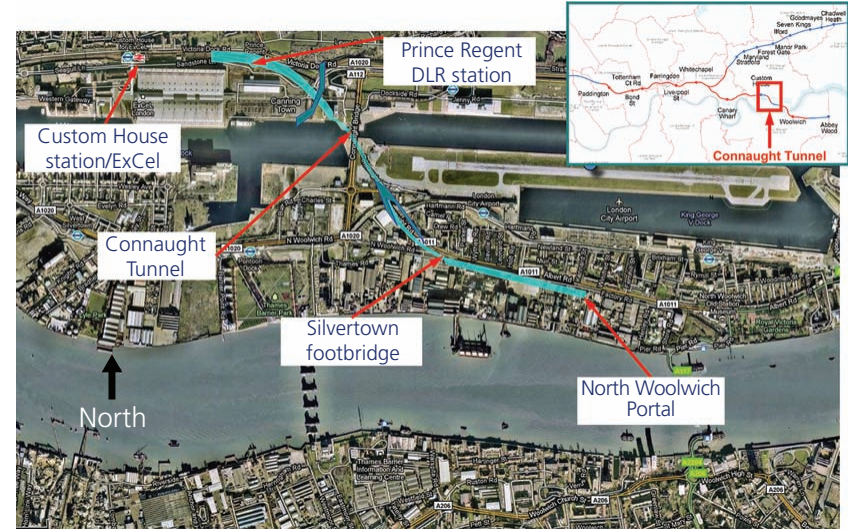

Figure 1. Location of the Connaught Tunnel

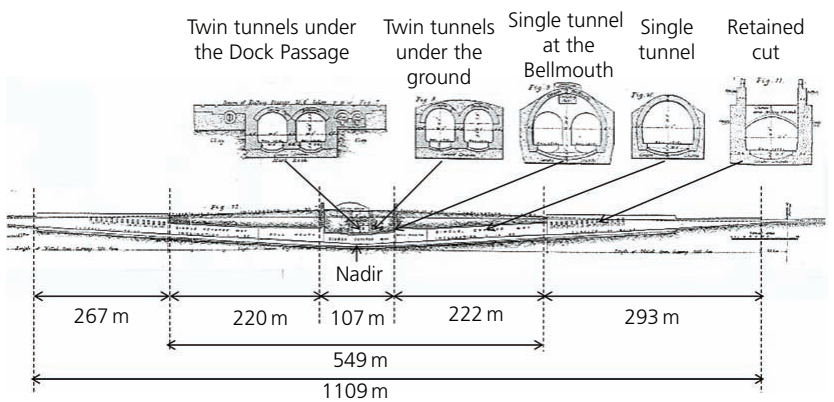

Figure 2. Longitudinal and cross-sectional profiles of the Connaught Tunnel

allow this arrangement to continue as it would have been difficult to provide and an effective water seal against the existing concrete and the new invert would need to be anchored into the ground to prevent uplift due to groundwater pressure. The new central drainage channel also directed surface water towards the tunnel nadir. The approach ramps are exposed and are therefore subject to rainwater. The approach ramp and tunnel are drained into a brick-lined pump sump shaft located on the northern side of the dock passage.

The portals to the single tunnels are of mass-concrete construction. The concave invert of each single tunnel shown in Figure 4 is formed of brickwork founded on mass concrete. The brickwork tunnel lining is seven brick rings (i.e. c. $900 \mathrm{~mm}$ ) thick, and the side-walls are haunched externally and formed of a $900 \mathrm{~mm}$ (typical) thickness of mass concrete battered down from the crown. Puddle clay was applied to the outside of both (i.e. east and west) single tunnels to provide some resistance to water ingress.

Each single tunnel widens as it approaches the twin-tunnelled central section, thus forming a bellmouth. The headwalls have been constructed in brickwork, which supports the brickwork ventilation shafts above. The shafts are $2.4 \mathrm{~m}$ in diameter, and the

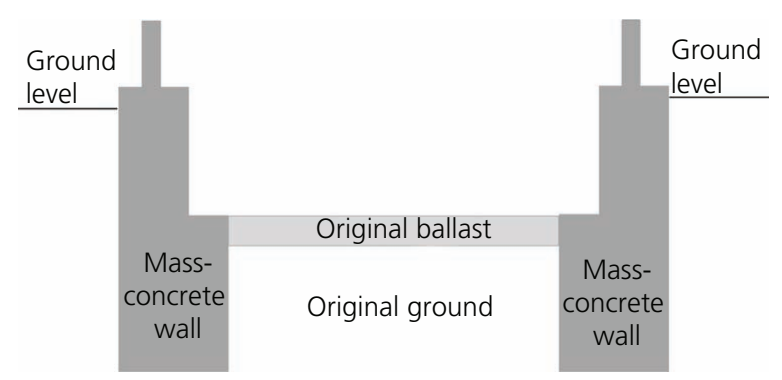

(a)

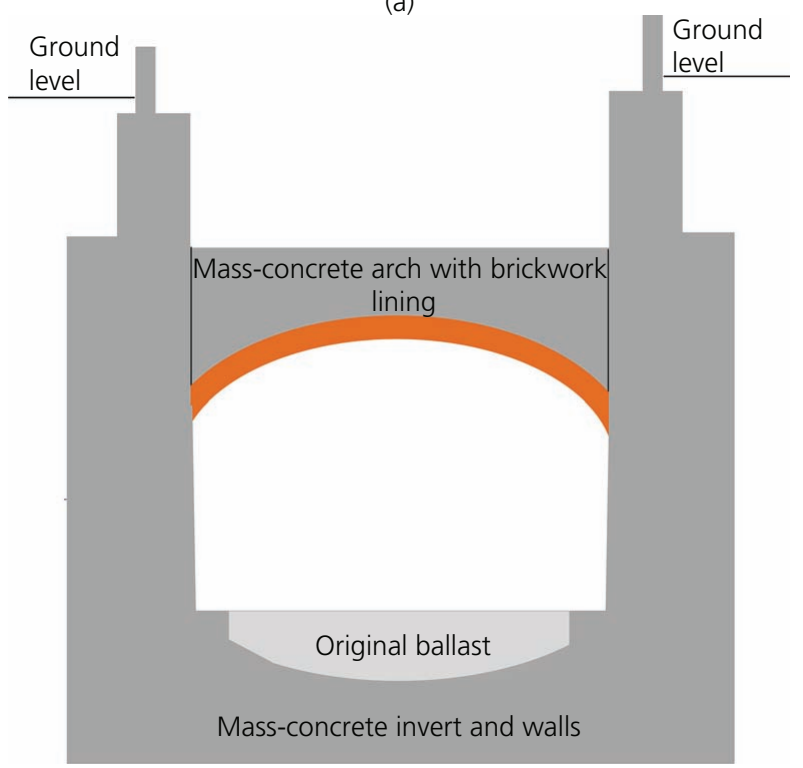

(b)

Figure 3. Approach ramps at top (a) and bottom (b)

base of each is $8.7 \mathrm{~m}$ below ground level with a further $4 \mathrm{~m}$ projecting above ground. The general condition of the tunnel and approaches is shown in Figure 5.

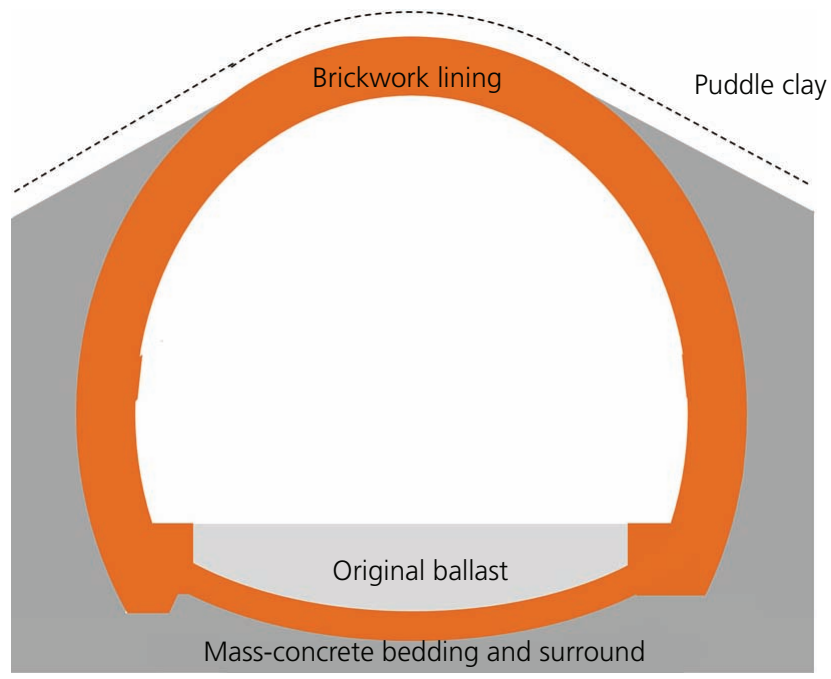

Figure 4. Single tunnel 


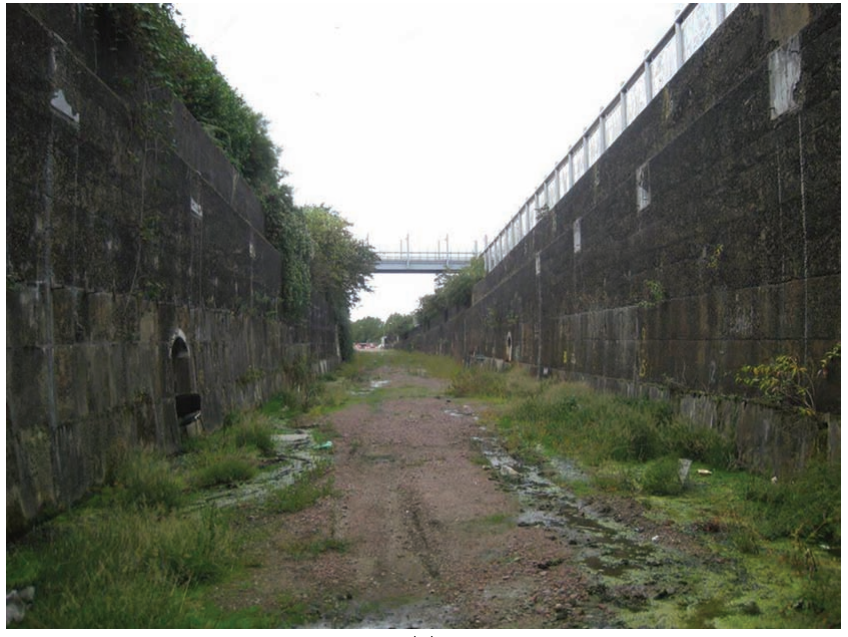

(a)

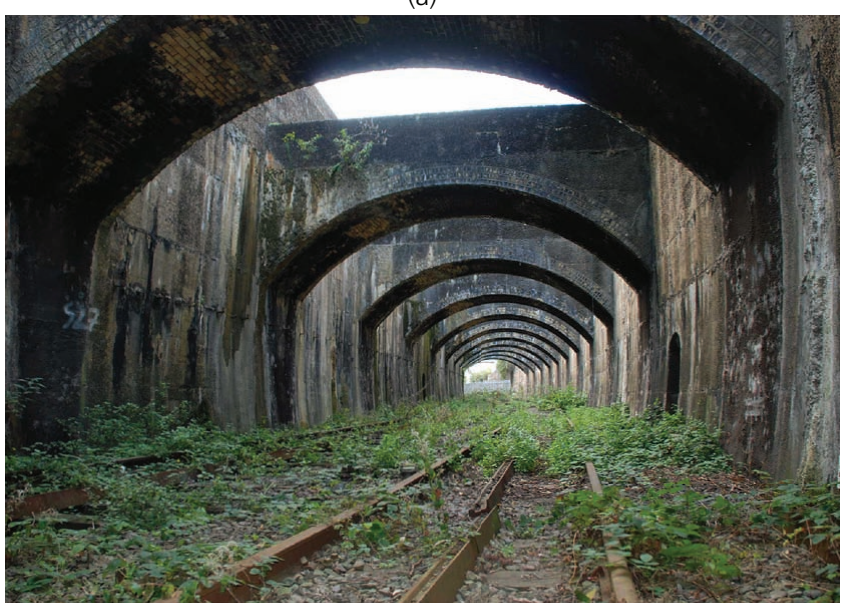

(c)

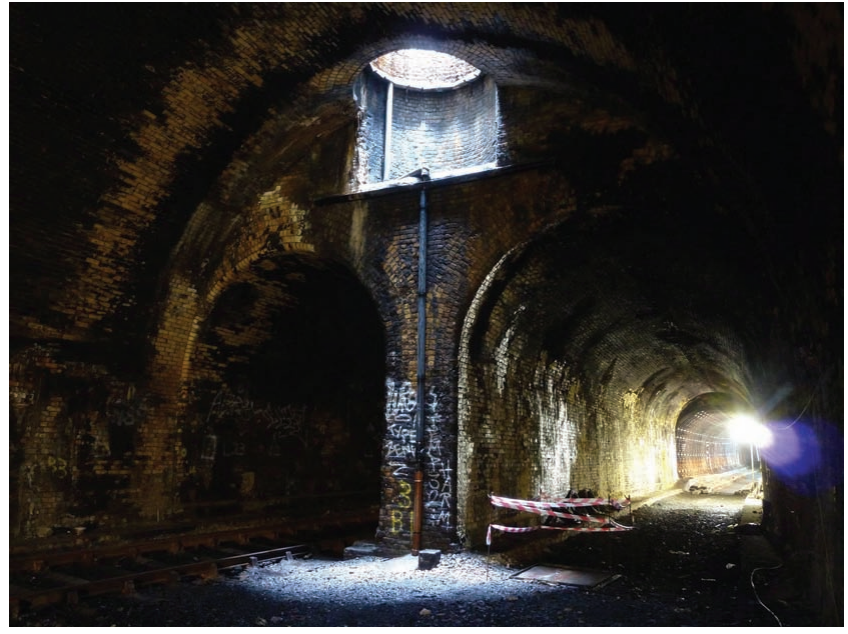

(b)

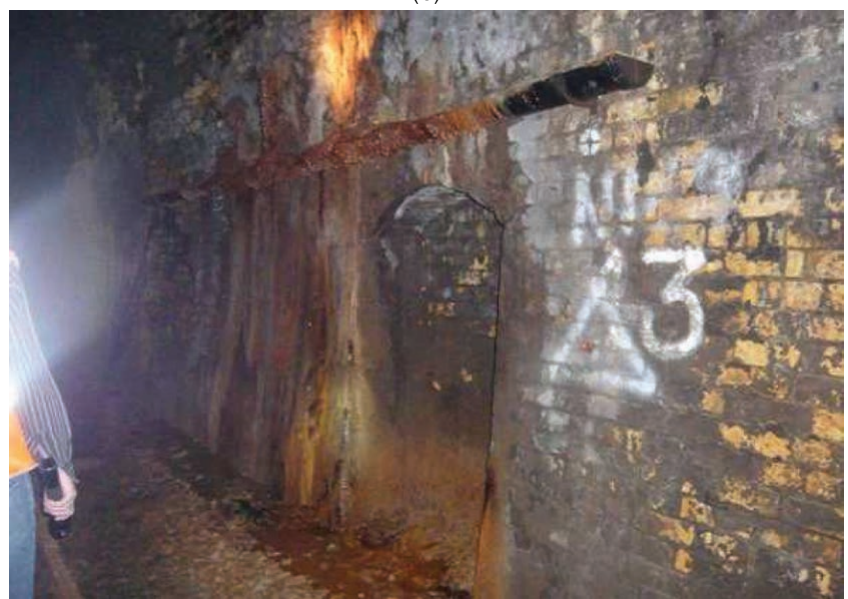

(d)

Figure 5. Existing condition: (a, c) approach ramps (b, d) and brickwork tunnel

\subsection{Strategy for assessment and repair}

The strategy for repair consisted of undertaking detailed surveys and testing of materials, identifying the requirements for the completed structure, identifying the existing and future causes of defects, assessing the structure and specifying the repairs.

\subsubsection{Surveys}

Records of tunnel inspections carried out between 1996 and 2006 were provided by Network Rail, and these provided valuable information of the condition of the structure when it was operational. This was supplemented by initial visual condition surveys of the approach ramp walls, which were undertaken for Crossrail during an earlier scheme design phase in 2007 and 2008. In order to develop the design, it was necessary to obtain information on the structural thickness and strengths of the materials used in the original construction. A series of cores through the tunnel and approach ramp side walls was therefore undertaken in 2010 and was followed by cores through the invert in 2011. This information, together with a specification for a detailed visual examination, was used for tender purposes for the main civil works of the project.

It was necessary to remove vegetation, moss, soot, graffiti and grime prior to carrying out the detailed survey, and this was implemented using high-pressure water cleaning. Trials, as shown in Figure 6, were undertaken to establish the most beneficial cleaning pressure and distance of the nozzle from the wall. It was concluded that the most favourable result was achieved by using 140 bar pressure, cleaning every $1 \mathrm{~m}^{2}$ of wall using a sweeping action for a period of $2 \mathrm{~min}$ and maintaining the pressure washer nozzle at approximately $300 \mathrm{~mm}$ from the face of the wall.

The tunnel drainage system discharged directly into the Royal Docks, and there was concern that contaminants in the waste water from the cleaning operation could pollute the docks. Therefore, the waste water was collected, tested and discharged into the local sewers under a permit to discharge groundwater and trade effluent. Solid calcification due to water ingress was removed by mechanical 


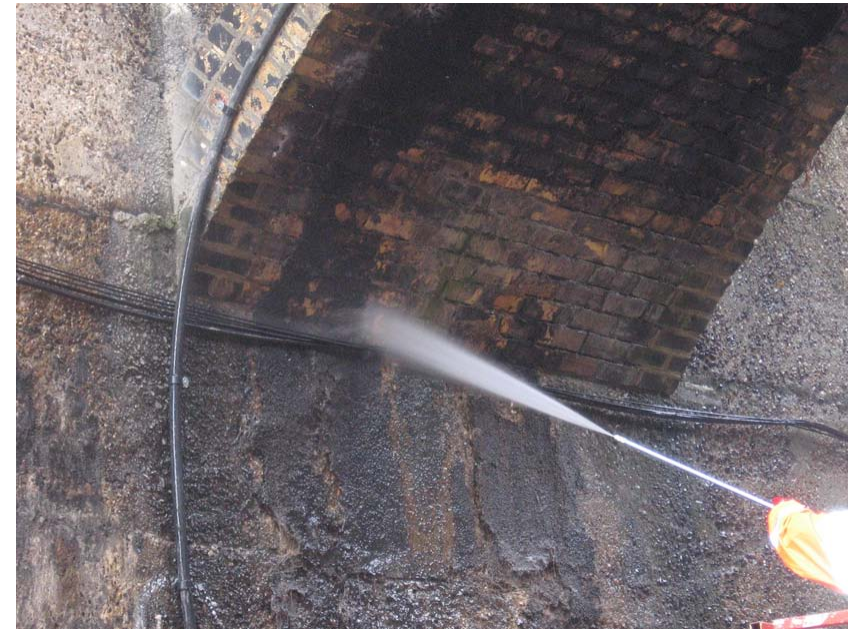

Figure 6. Cleaning trial in progress on the brick-lined approach ramp arches

means, with care taken not to damage the face of the structure. Vegetation, along with any roots, was pulled out.

The surveys, which were carried out in 2013, were recorded in accordance with NR/L3/CIV/0006/4C, Examination of Structures Record of Tunnel Examinations (Network Rail, 2009c). This approach provided consistent and sufficiently detailed information to develop the repair strategy and details. The survey required that all structural surfaces should be checked for hollowness by tapping, better known as the drummy test.

\subsubsection{Materials}

Engineering: an Illustrated Weekly Journal records that 'the gault bricks are supplied by the Aylesford Pottery Company' (Anon, 1878). The strength of the brickwork was established by coring the tunnel invert. The minimum direct core compressive test result recorded for the brickwork was $16 \mathrm{MPa}$, and, following the application of material and partial load factors, the working compressive strength capacity was determined to be $3 \cdot 2 \mathrm{MPa}$. Core compressive test results from samples of the mass-concrete haunching behind the brickwork were assessed based on BS EN 13791:2007 (BSI, 2007), and a working compressive strength capacity of $12 \cdot 6 \mathrm{MPa}$ was established.

The mortar used for the brickwork was surprisingly strong, and, during brickwork removal, it was noted that adherence to the bricks was good.

The journal also records that 'the concrete is made from a valuable bed of gravel which underlies the peat at various levels throughout the estate' (Anon, 1878) and that Portland cement was used in the works.

The material properties of the concrete were assessed based on the results of concrete compressive core tests, and a design compressive strength resistance of $10 \cdot 3 \mathrm{MPa}$ was calculated based on BS EN 13791:2007 (BSI, 2007). The cores also provided dimensional information on the thickness of the structure.

The concrete was unreinforced and was poured in layers of variable height. The construction joints were clearly visible due to gradual erosion.

\subsubsection{Structural assessment}

Calculations were produced to demonstrate that the structural capacity of the existing structure was adequate based on intrusive surveys to establish material strength, thickness and condition.

The structures were assessed in accordance with the requirements of London Underground Limited (LUL, 2010) and the standards that appertained at the time.

An example of the method of assessment for the brick arch tunnel is contained in the publication by Network Rail (2009b).

Movement monitoring was used throughout the project, and the results confirmed that the structures were stable and checks to substantiate continued movement were not required.

\subsubsection{Design and functional requirements}

The repairs are expected to achieve a life expectancy of 120 years for durability. The reason for this is that there would be limited opportunities for future tunnel maintenance when the railway is operational given that work would need to be carried out during engineering hours when the railway would be closed to passengers. Engineering hours also need to include mobilisation and checks prior to the railway becoming operational again, so the available time for carrying out repairs is further restricted. An additional constraint is that the line may have to remain open during these hours to enable engineering trains to support maintenance work elsewhere on the line, thereby restricting access. The repairs therefore needed to be as maintenance-free as possible.

The repair strength needs to be at least the same as the strength of the existing parent material. This requirement is intended to ensure that the assessment and any future assessments are not limited by the strength of repairs. The preparation of the repairs did not require structurally significant areas to be removed, and the final repairs were not required to accommodate load. However, particular care was used to make sure that repairs were fully embedded into the structure as local shallow repairs are known to eventually spall in the long term.

Resistance for limiting water ingress into new tunnels is defined relative to the axis (the horizontal centre line) of the tunnel. Tunnels were required to be free from all leakage, seepage and damp patches above the axis level. Below the axis, the limitations were damp patches and minor weeping of joints with less than $0.24(1 / \mathrm{d}) / \mathrm{m}^{2}$ from any separate square metre. The requirement was achieved for the new reinforced-concrete works in the tunnel. Whole-life costing 
of the tunnel works allowed for continued groundwater ingress through the existing structure. Therefore, while best efforts could be made to reduce water ingress, provision existed to drain residual ingress. Water ingress from the tunnels could not be permitted to leak onto the overhead line equipment as potentially aggressive groundwater could corrode the equipment.

The repairs could be subject to train fires, the intensity of which is defined by the RABT-ZTV (Eureka) fire resistance profile curve. The repairs need to remain integral with the structure in the event of fire, and repair materials, such as epoxy-modified grouts, should not be used as they emit noxious gases, which could hinder firefighting and rescue efforts.

The repairs need to be robust enough to accommodate new fixings, particularly for line-wide equipment such as cable management systems and firefighting dry mains. A shallow repair could adversely affect the pull-out capacity of fixing anchors, and large areas of shallow repairs need to be avoided. Brickwork repairs involving replacement of bricks need to be tied back fully to the original structure.

Network Rail (2009b) drawings exist for brickwork repairs. These drawings were used as far as possible throughout the works to provide standardisation. Concrete repairs were generally of a nonload-bearing nature, and the repairs were designed to suit the particular circumstances.

\subsubsection{Potential future causes of defects}

Potential future causes of deterioration also had to be considered. Changes in loading patterns on the structure could occur due to oversite development, ground dewatering, rising groundwater and lowering of the dock water level.

Water ingress could increase due to rising groundwater levels, leakage from existing and future water supply services and drains, replacement of relatively impermeable ground with granular fill in future excavations alongside the tunnel and new penetrations through the walls.

\section{Common defects}

\subsection{Water ingress}

The water ingress in the western approach ramp was approximately 20 litres/s, and in the eastern approach ramp, it was approximately 10 litres/s prior to work starting on-site. The majority of the ingress was due to groundwater infiltration through the existing ground and ballasted track in the ramps. New concrete inverts were provided in the ramps (Wilde and Craft, 2015), but these required groundwater pressure relief weepholes to prevent uplift of the invert. Following repairs, the total amount of water ingress remains as it was, subject to fluctuations in groundwater levels.

The top of the approach ramps are at a high enough level to prevent flooding of the tunnel in all other conditions.
Active and historic water ingress was present throughout the tunnel with associated calcite, silt and efflorescence deposits. Ingress was more prominent in the approach ramps where Made Ground, alluvium and River Terrace deposits existed behind and the walls. The majority of the water ingress in the approach ramp emanated from the inverts and walls immediately above the invert. An example is shown in Figure 7.

The puddle clay surrounding the brickwork tunnel limited water ingress from peat and River Terrace deposits, as did the Lambeth Group clays beneath the tunnel invert. Water ingress was prominent at voids, unsealed service penetrations, cracks and construction joints or, more generally, the least path of resistance. Water ingress can result in the degradation of structural elements through chemical attack, abrasion and freeze-thaw cycles.

Active water ingress repairs were carried out only for Network Rail severity ratings of W1 and W2 (water ingress under pressure and wet running water, respectively) (Mair et al., 1996). Defects with Network Rail category W3 (wet dripping water) were acceptable provided that the drips were not above the axis as per the requirements.

The specified repairs for brickwork consisted of cement grout containing graded aggregates and an anti-shrink additive to provide a $28 \mathrm{~d}$ cube strength of $40 \mathrm{~N} / \mathrm{mm}^{2}$, based on the requirements of the Network Rail (2009b) drawings. Following the initial repairs, the water ingress from the brickwork tunnel linings was not prolific, but there were still a few unacceptable areas of leaks above the tunnel axis. Consideration was given to the use of an inner lining sheeting to manage water ingress. Sheeting would have obstructed access for future inspection of the tunnel structure, and calcification or other debris could build up in the cavity between the sheeting and the structure.

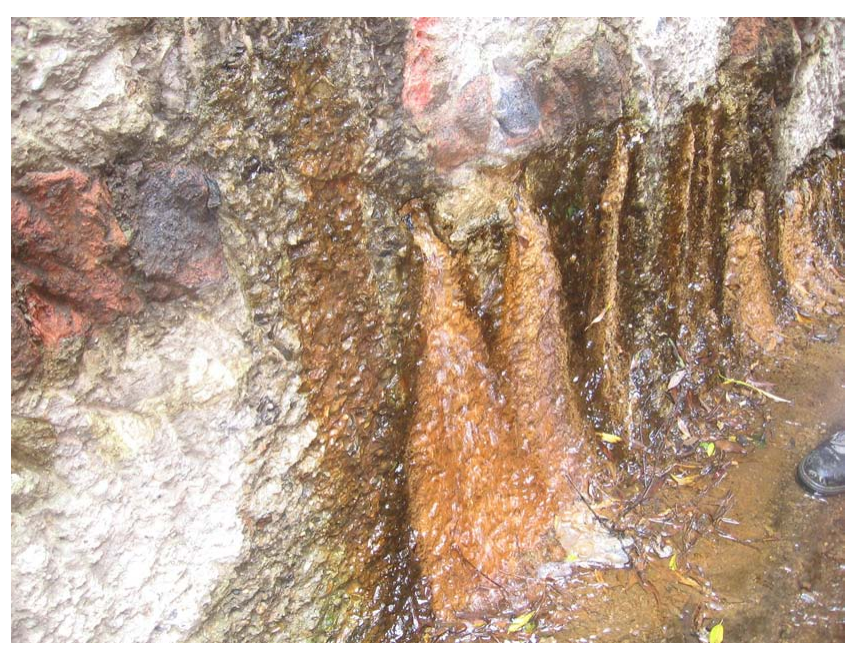

Figure 7. Water ingress through existing concrete 
The brickwork tunnel lining had been surrounded in concrete and puddle clay during the original construction, and, as the brickwork had been well built with the minimum of voids, water paths were less well connected. Further isolated repairs using hydrophilic flexible polyurethane grout capped off with a single-component cementitious mortar containing microsilica and polypropylene fibres were undertaken.

The cause of the groundwater leakage in the concrete approach ramps should ideally have been eliminated so that repairs are not required. The options considered were coring through the walls to relieve the water pressure in the ground behind, incorporating a land drain behind the structures to relieve the water pressure and provision of an external membrane or ground treatment to prevent water seeping into the structure.

Coring through the structure was not an option as the water ingress would have added to the drainage flows into the tunnel, jetting of the water may have occurred and fines could have been drawn out of the ground behind the structure, resulting in settlement. The incorporation of land drains discharging into an external sewer would have required consents for what could prove to be a substantial quantity of water. Installation of an external membrane or ground treatment to prevent water seeping into the structure would have affected third-party properties outside the railway. Excavation for a membrane could affect the stability of adjacent structures, and the effectiveness of the membrane would only be as good as the quality of the joints in the membrane. Grouting behind the tunnel walls would have depended on the ground conditions and confidence that the grout would not pollute watercourses.

The initial phase of concrete repairs was targeted at major water ingress locations. The repair method involved locally opening up the existing concrete to a $100 \mathrm{~mm}$ depth and injecting hydrophilic flexible polyurethane grout to stem water ingress. The repair was completed using a non-shrink cementitious mortar infill to provide durability. The contractor used hydro-demolition and suitable protection to remove defective concrete and open up defects for repair. This proved to be safer and quicker than mechanical breakout. An example of a completed concrete repair is shown in Figure 8.

Following the initial phase of repairs, it was evident that water ingress was migrating to previously dry water paths in the structure. Further water ingress repairs were not feasible given the number of original construction joints and potential water paths in the structure. It was therefore concluded that the best course of action was to prevent water ingress above the axis and divert any surplus water ingress down to the track drainage system.

Problems associated with residual ingress were the build-up of calcite and microbiological residue on the line-wide services. Consideration was given to chasing vertical drainage channels into the structure, but the difficulties with this solution included coordination of the chases to suit the line-wide cable management system fixings and the maintenance of vertical channels as the

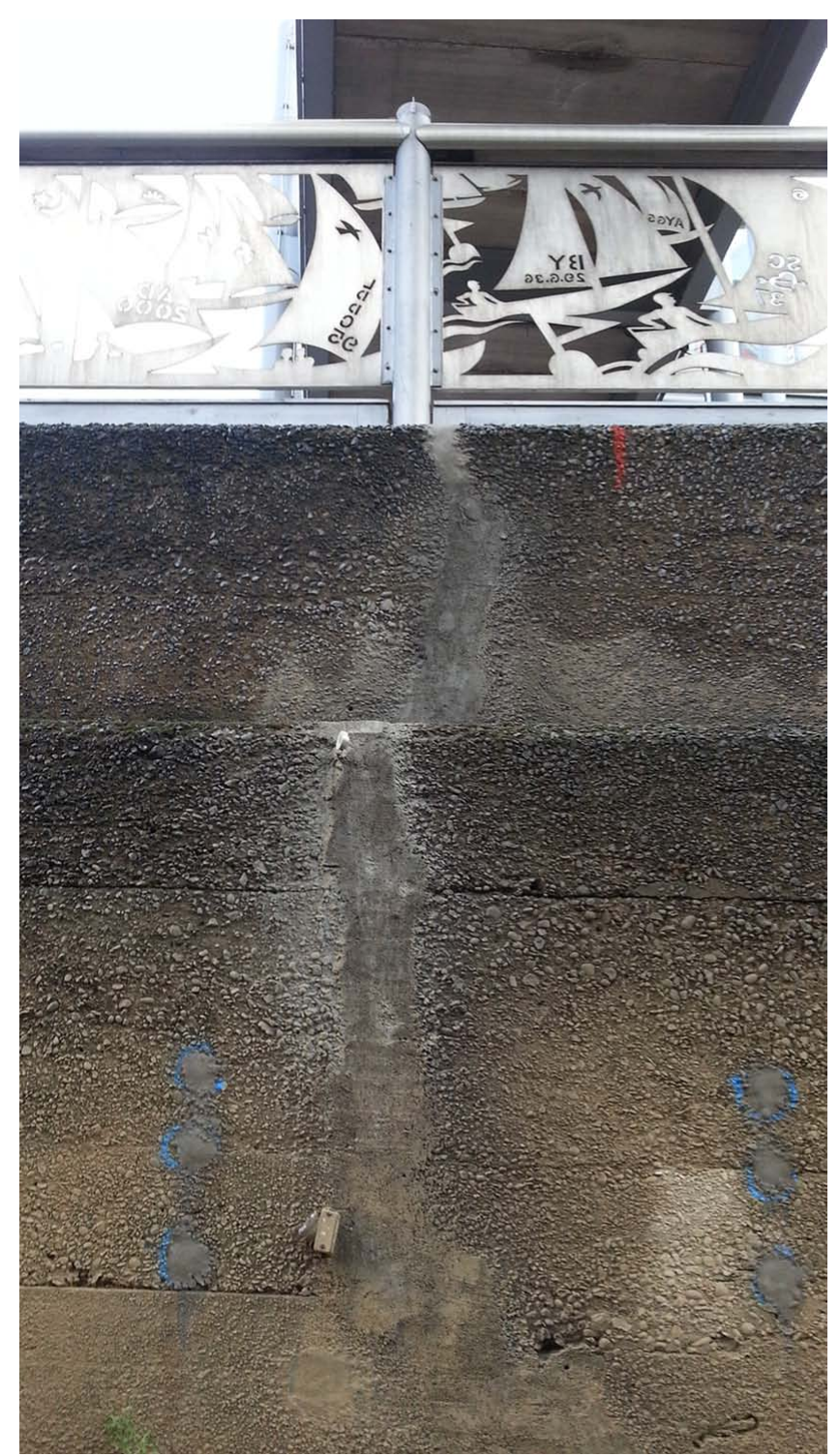

Figure 8. Completed vertical crack concrete repair

latter could eventually become clogged with calcite. The proposed solution was to inject construction joints further with hydrophilic flexible polyurethane grout and incorporate pressed metal deflectors above the cable management system.

The waterproofing system used on top of mass-concrete approach ramp arches was a sprayed methyl methacrylate resin membrane in conjunction with compatible preparatory products, commonly used for bridge deck waterproofing. The top surface of the arch was prepared by grit blasting. Defects less than $20 \mathrm{~mm}$ wide were infilled with a liquid sealant, and larger defects were infilled using a rapid-hardening repair mortar. A primer was then applied followed by a first coat of the membrane and a scrim coat where cracks were still evident. The primer was also thickened where potential ponding could occur. The second coat was then applied 
to a maximum thickness of $3 \mathrm{~mm}$. The system returned $150 \mathrm{~mm}$ up the approach ramp walls to ensure that the joint between the arch and wall was sealed.

\subsection{Cracking}

Generally, vertical cracks were evident at changes of structural types, typically along the approach ramps where there was originally a change from integral invert slabs to retaining walls without inverts. Thermal cracking was also evident on the approach ramp walls with vertical cracks at regular intervals.

The criteria used for determining if crack repairs were required was based on cracks being $5 \mathrm{~mm}$ wide or less requiring only cosmetic repairs according to building damage classification 2 after Burland (1995) and Mair et al. (1996). It was determined that surveyed cracks which were more than $5 \mathrm{~mm}$ wide were not structurally significant and the specified repair for cracks exceeding $5 \mathrm{~mm}$ was by grouting only, similar to the repairs for water ingress.

Many of the cracks observed in the brickwork during the survey were through single bricks and were not deemed to have an impact on structural performance. Had horizontal cracking occurred in the brickwork, then the cause would likely be due to lateral ground movements and potential ovalisation of the tunnel. The use of epoxymodified grouts was accepted outside running tunnel areas during site works - that is, repairs to the brickwork lining to the approach ramp arches. The high-performance, injectable, cementitious, nonshrink grout used for crack stitching was not required to reach the $1 \mathrm{~d}$ strength specified on Network Rail (2009b) drawings, but it was still required to achieve the $28 \mathrm{~d}$ strength. The tunnels were nonoperational at the time of the repairs; therefore, there was no need for early-age strength to bring the railway back into operation as soon as possible.

Vertical cracking of varied severity was found in the approach ramp concrete walls and are likely to have been caused by historic settlement over time and thermal movements.

Dry cracks were repaired with a non-shrink cementitious injectable grout using grout seals and hose packers. An example of a completed concrete repair is shown in Figure 8.

\subsection{Spalling}

The worst cases of spalling occurred at the brick lining of the approach ramp arches. This was most likely due to the effects of water ingress and subsequent erosion due to chemicals and the freeze-thaw cycle. The specified repair was to remove and replace defective brickwork to match the existing strength and bond using the temporary support details shown in Network Rail (2009b) drawings. Open joints and missing mortar were also evident, and these were repaired if the depth of the defect exceeded Network Rail severity category J1 (greater than $50 \mathrm{~mm}$ ) (Mair et al., 1996), the greatest acceptable depth as determined by the structural assessment. Repointing in class M6 (ii) mortar to BS EN 1996-1-1:2005 $+\mathrm{A} 1: 2012$ (BSI, 2005) was specified. During the works, it was agreed that colour matching of mortar was not required as the tunnel brickwork was not exposed to public view. The joints were flush and brush finished. However, the mortar joints on the exposed aboveground brickwork surfaces of the vent shafts did need to be colour matched and pointed to match the existing brickwork.

\subsection{Voids}

Voids had been mechanically formed for specific purposes, either during construction or as a later modification for line-wide services. Some voids were the result of core holes for intrusive investigation or for grouting during the main civil works. Others were likely to be the result of gradual water erosion and disintegration. Additional repairs also included preparation and infilling of voids required for temporary works carried out subsequent to the survey.

The specified repair of voids in brickwork exceeding a single brick size involved carefully breaking out sufficient brickwork to enable the sides of the void to be toothed, cleaning out and infilling with new brickwork. Repairs not exceeding a single brick size required spot replacement of brickwork. It was agreed during site works that date-stamping of new brickwork used in repairs was not required as record drawings showing the locations of the repairs would be available for future reference. It was difficult to remove individual bricks in some locations due to the high strength of the original mortar, and after preparation of voids, they were filled with a single-component cementitious mortar containing microsilica and polypropylene fibres.

Some repairs over larger areas were achieved by the removal of bricks to a sound surface and pinning and grouting new brickwork back to the existing structure using a highperformance, injectable, cementitious, non-shrink grout. The preparation required for this type of repair is shown in Figure 9.

The grout holes in the brickwork were then plugged with a singlecomponent cementitious mortar containing microsilica and

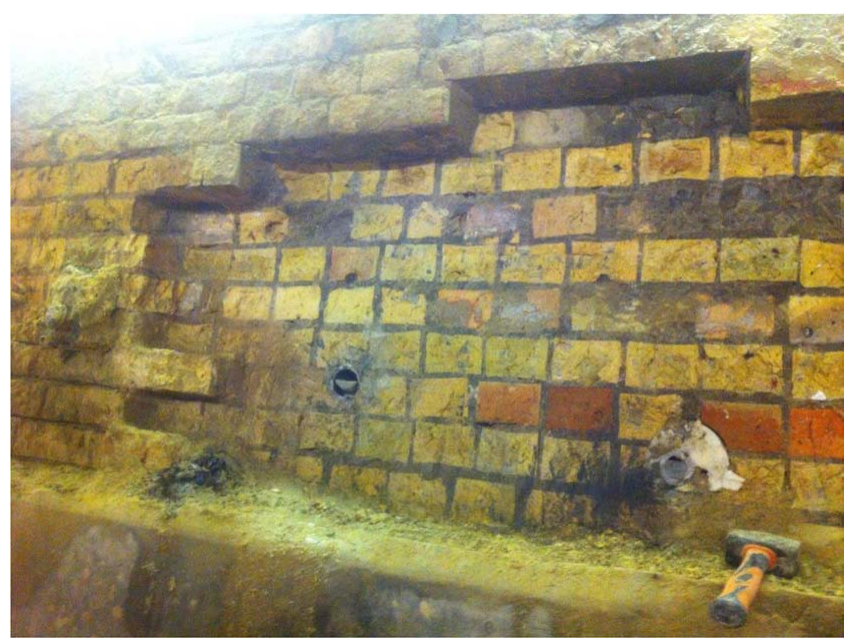

Figure 9. Preparation for brickwork void infilling 
polypropylene fibres to a depth of at least $100 \mathrm{~mm}$. It was agreed that some repairs involving replacement bricks could be carried out using concrete infill to a minimum depth of at least $100 \mathrm{~mm}$ for small areas and $200 \mathrm{~mm}$ for larger areas. The concrete infill was at least as strong as the brickwork, and the brickwork had been prepared to accept the repair - that is, fully bonded.

A polymer-modified, dry-spray, structural repair concrete was also used for some brickwork replacement repairs in conjunction with dowel bars fixed into the brickwork using a high-performance, injectable, cementitious, non-shrink grout.

The drummy survey of brickwork indicated that the bond between the rings of brickwork forming the tunnel lining generally remained in good condition. There were isolated instances where areas of drummy brickwork were identified, indicating that separation of the brick rings might have occurred. It was therefore necessary to understand how deep the delamination of the structure may be from the internal face of the structure in order to specify the type of repair. Cores were requested to determine the defect depth, and a range of repair options was specified based on the Network Rail (2009b) drawings, depending on the outcome of the investigation. It was subsequently established that delamination had occurred near the internal surface; therefore, localised instances of drummy were repaired by cross-pinning and grouting. Repairs were also required to drummy brickwork patches not exceeding $1 \mathrm{~m}^{2}$ in the linings to three of the west approach ramp arches, as shown in Figure 10.

Temporary support to the brickwork was provided using steel straps anchored to sound brickwork, and grouted pins were used, as described in Section 3. Where pinning was carried out, the $16 \mathrm{~mm}$ dia. dowel bars were installed in $25 \mathrm{~mm}$ dia. holes drilled into the brickwork to facilitate the injection of high-performance, cementitious, non-shrink grout. Steel pins were not readily available in grade 1.4436 during the site works; therefore, grade $1 \cdot 4362$ steel was used instead.

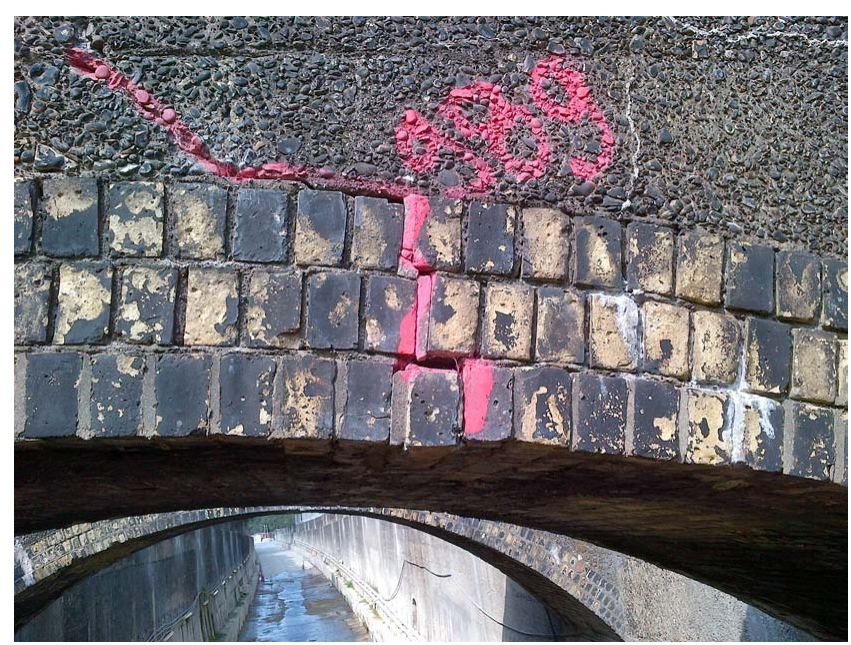

Figure 10. Delaminating brickwork, arch lining
It was determined from the structural assessment that structural repair of voids was needed for concrete greater than $50 \mathrm{~mm}$ deep. Repairs were therefore specified if the void depth exceeded $40 \mathrm{~mm}$ (Network Rail S3 severity rating (Mair et al., 1996)). The void was to be prepared by chiselling out to a size $30 \mathrm{~mm}$ greater than the defect and filled using a non-shrink cementitious mortar. A similar strategy was applied to concrete spalling and residual voids following the removal of redundant fixings. Where original embedded temporary works timbers were found, timber was removed and the void was prepared for grouting by removing debris, cleaning with compressed air and under reaming the void sides by $5 \mathrm{~mm}$ to ensure that the repair would be wedged in. The void was then closed up with formwork and cement grouted, ensuring that the grout was poured above the required level to eliminate air pockets. Minor repairs to concrete on the approach ramp not exceeding $0.25 \mathrm{~m}^{2}$ and not less than $100 \mathrm{~mm}$ deep were carried out using an acrylic-polymer-modified, high-build structural repair mortar. The surfaces were prepared such that the repair would be wedged in to prevent it further from falling out.

\subsection{Redundant fixings}

If redundant fixings remain embedded in the structure, they are likely to deteriorate, clash with new fixings or encroach on the space required for line-wide equipment. Fixings made of stainless steel and cast iron will not appreciably deteriorate and could therefore be retained, but most of the existing fixings were of iron or steel and the expansive action of corrosion had resulted in local spalling of the structure at the fixing locations. There was a requirement to maintain tunnelling monitoring points and temporary fixings for temporary services during the repair works; these would be removed when redundant.

The type of repair for redundant fixings in brickwork was dependent on the depth of the defect, which would not necessarily be known until the fixing had been removed. If the repair depth exceeded $50 \mathrm{~mm}$ (Network Rail S1 severity rating (Mair et al., 1996)), then spot replacement of brickwork was to be carried out. Small voids were to be repaired in a similar manner, with larger voids being infilled with fully bonded brickwork. During the site works, it was agreed that small-diameter holes in brickwork could be repaired using a single-component cementitious mortar containing microsilica and polypropylene fibres due to the previously mentioned difficulties with spot replacement of brickwork.

\subsection{Previous repairs}

It was observed that previous brickwork repairs were in a satisfactory condition, and no remedial work was required.

\subsection{Vegetation growth}

Vegetation had accumulated on flat surfaces, corners and cracks outside the tunnel. The use of chemical weed killers for vegetation removal was constrained by subsequent rainfall or accidental spillage, discharge into the drainage system and potential contamination of the Royal Docks. An environmentally friendly chemical weed killer could not be found, and vegetation was removed by mechanical means and high-pressure water cleaning. Small concentrations of 
Connaught Tunnel, UK: condition

and repairs

Wilde

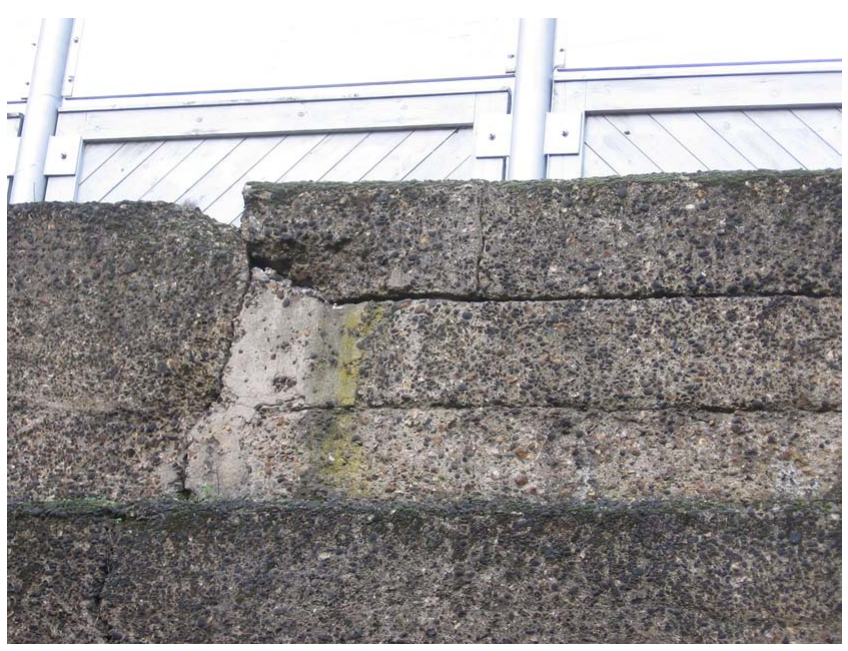

Figure 11. Example of approach ramp parapet requiring removal and replacement

chemical weed killer may have been acceptable, subject to controls being in place, but the dosage rate may not have been adequate to kill the weeds effectively. Technology for sprayed water near the boiling point may be available for application from rail-mounted vehicles, and environmentally friendly chemical solutions may also be developed in future.

\subsection{General}

The extent of some of the defects was not apparent until all of the defective material had been removed, and some of the repair extents were correspondingly adjusted. The changes were incorporated on redline drawings to enable the future understanding of what had changed and where.

A few sections of the existing concrete parapets in the approach ramps had suffered from vertical thermal cracking, spalling at construction joints and loosening of connectivity to the retaining walls due to freeze-thaw cycles. An example is shown in Figure 11. The parapets were therefore removed in these sections and replaced with new fencing.

\section{Bomb damage}

Bomb damage occurred to the western single brick arch tunnel in September 1940. The damaged area required a repair measuring approximately $10 \mathrm{~m}$ long by $5 \mathrm{~m}$ high to the haunch above the future eastbound track. The 1940 repair consisted of a concrete infill to suit the internal profile of the tunnel. Reinforcement used on the internal face subsequently became exposed due to corrosion, resulting in spalling concrete. It is likely that the bombing also disturbed the clay lining over the tunnel and water ingress resistance was impaired, as a downpipe to drain leakage down to track level had been installed. The original bomb damage repair is shown in Figure 12.

Core samples established that the concrete infill was at least as thick as the tunnel lining, that the concrete strength was in excess

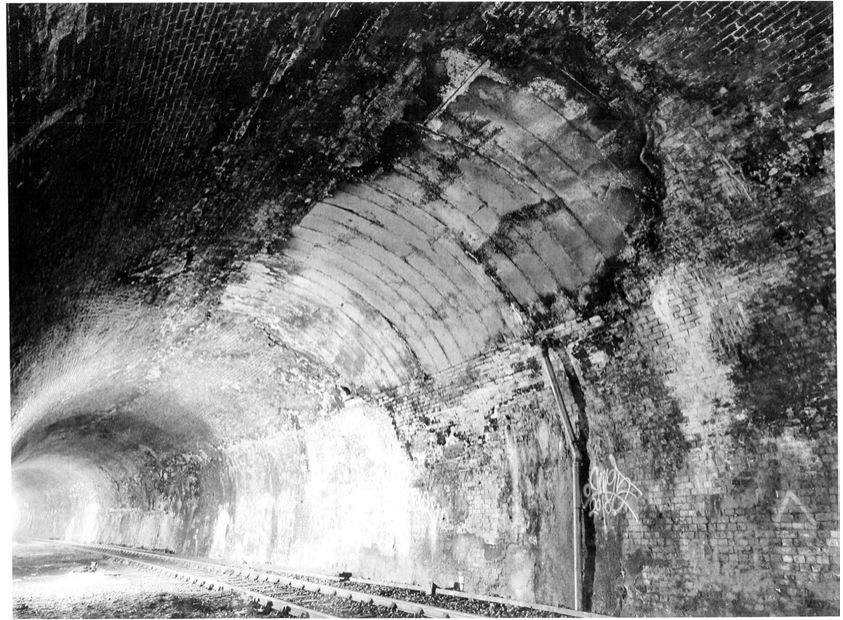

Figure 12. Original bomb damage repair

of the existing brickwork strength tested elsewhere in the tunnel and that clay still existed behind the repair. It was also established that the bond between the concrete and brickwork was adequate as the cores remained intact at the interface of the materials.

Consideration was given to removing the existing repair concrete and replacing with either new brickwork or concrete or providing a structural concrete sleeve over the existing repair. Neither of these options was feasible due to safety, durability, affordability or space-proofing concerns.

The structural assessment concluded that it was possible to remove sequentially $1 \mathrm{~m}$ wide strips of concrete of sufficient depth to expose the reinforcement completely, so that it could be removed as shown in Figure 13. The concrete could then be reinstated using sprayed concrete.

Drummy surveys established that the brickwork rings adjacent to the lining were delaminated; the priority was therefore to repair

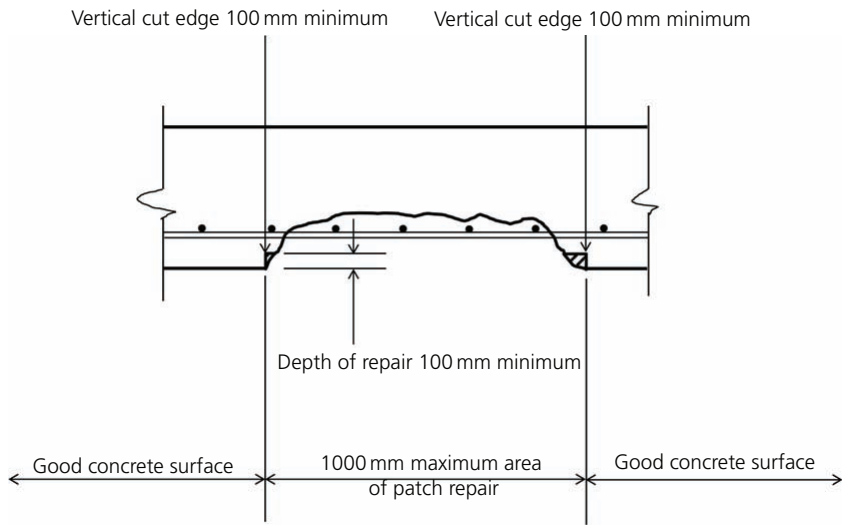

Figure 13. Removal of original bomb damage repair concrete in $1 \mathrm{~m}$ strips 
Engineering History and Heritage

Volume 172 Issue EH2
Connaught Tunnel, UK: condition

and repairs

Wilde

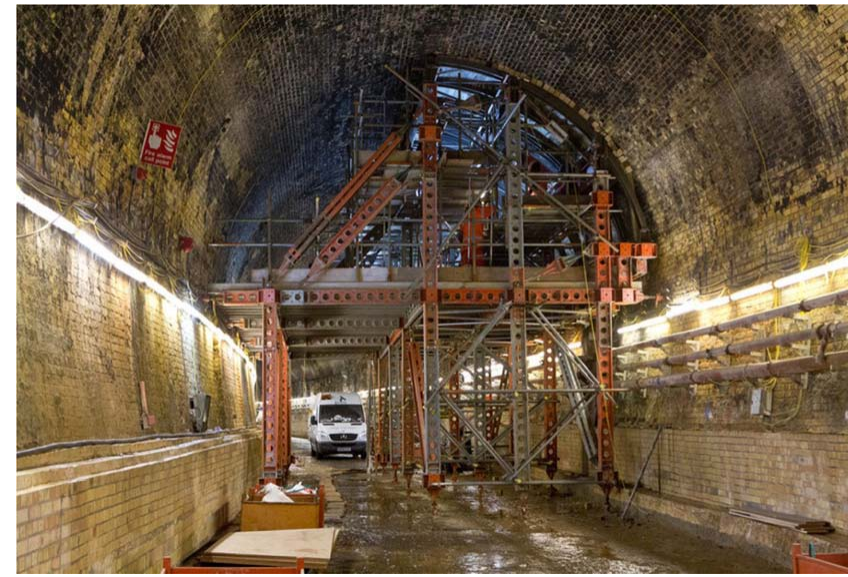

Figure 14. Temporary support for drummy brickwork repair

the brickwork prior to carrying out the remedial works to the existing concrete repair, to avoid disturbance of the brickwork. The brickwork repair involved cross-pinning and grouting using a temporary support system to hold the brickwork in place for drilling and subsequent grouting pressures. A photograph of the temporary support system is shown in Figure 14.

It was apparent that it would not be feasible to cross-pin given the spatial constraints of the temporary support ribs. The pins were therefore installed perpendicular to the intrados and at reduced centres, generally in accordance with the recommendations given in Ciria's report C671 (McKibbins et al., 2010). The undrilled length of the brick from the end of the stitch was increased from 100 to $150 \mathrm{~mm}$ based on the advice of the specialist repair subcontractor in order to reduce the risk of overdrilling and potential water ingress. The cross-pins were grouted using highperformance, injectable, cementitious, non-shrink grout. The final $50 \mathrm{~mm}$ of the pin hole was plugged with high-build cementitious mortar in order to comply with fire resistance requirements. The brickwork was drummy tested again to identify areas that potentially contained voids on the assumption that the highperformance, injectable, cementitious, non-shrink grout would not have fully grouted all the voids. Injectable microfine cement grout was then used to fill any further voids. The drill holes for the grout were plugged with high-build cementitious mortar. When the grouts had achieved their respective specified $28 \mathrm{~d}$ strengths, the temporary works were removed.

The reinforcement in the original bomb damage repair concrete could then be removed as originally planned. Hydro-demolition of the concrete was used to expose the reinforcement and polymermodified, dry-spray, structural repair concrete was used to reinstate the concrete and fill the core holes used to investigate the concrete. The sprayed concrete was treated with a curing membrane.

It was not possible to remove the existing downpipe used for managing water ingress as the flows through the pipe were too large to repair. The existing downpipe would have also clashed with future cable management systems and therefore had to be removed. The wall was cut back locally to allow a new downpipe to be installed.

\section{Health and safety}

High-level access was achieved using mobile elevating work platforms and alloy access towers. Hydro-demolition and sprayed concrete operations required protective screening and trained specialist operatives. The use of hydro-demolition reduced the risk of hand-arm vibration due to hand breaking. Chases were cut using abrasive wheels; therefore, dust control was required. Hazardous repair materials were identified, and suitable precautions were taken. The effects due to noise were controlled. Temporary ventilation, structural movement and gas monitoring was used in the tunnel throughout the project. Vehicle and personnel access routes were segregated, and repair works were coordinated with other concurrent operations on-site.
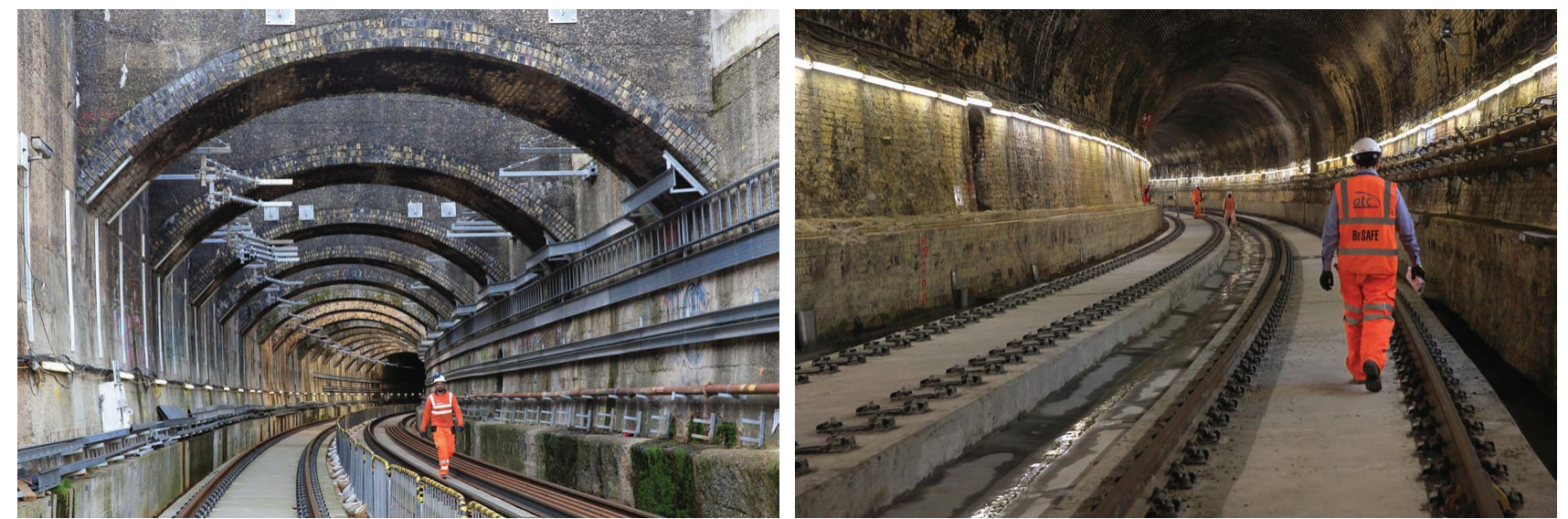

Figure 15. Completed tunnel repair works 


\section{Conclusions}

The most significant defects were lining delamination (due to the potential collapse of brickwork) and embedded ironwork continuing to corrode, leading to local spalling and loose debris. Water ingress defects created the most problems as water would invariably find alternative latent paths around repairs. The repair of the bomb-damaged area was the most costly single item to deal with as it involved temporary works and narrowed access through the tunnel for other construction activities.

The primary residual defect is that of water ingress and the build-up of calcite resulting from the ingress. Particular emphasis was placed on repairing above-axis ingress as far as was reasonably possible.

The tunnel repairs, which were based on Network Rail guidance and other current practice, will reduce future maintenance requirements for the existing tunnel, thereby benefitting railway operations. Unavoidable water leaks in the tunnel remain and will require maintenance; however, the cost of rectifying the leaks, if rectification could have been successfully achieved, would have been prohibitive.

Prior to the Crossrail Act of 2008, consideration was given to the whole-life costing of reusing the tunnel as opposed to boring new tunnels, and the cost of new tunnels was estimated to be higher than the costs of repairs, maintenance and ongoing drainage requirements to reuse the existing tunnel. Relevant reports are now dated and could not be retrieved. However, considerations would have included the variability of ground conditions for new tunnelling works and the cost of an underground station at Custom House. The reuse of the tunnel has bought back to life a valuable asset that would have otherwise been redundant and would have incurred ongoing maintenance costs due to continued dilapidation. In the long term, it is likely that the redundant tunnel would have incurred substantial costs for infilling. A fine example of Victorian engineering has been preserved from a heritage point of view (Figure 15).

\section{Acknowledgements}

The author acknowledges Crossrail Limited, the client, for the figures and images; Bechtel/Halcrow, in charge of project management and central engineering; Arup/Atkins, the $\mathrm{C} 122$ bored tunnels' framework design contractors; Vinci Construction UK (Taylor Woodrow Civil Engineering), the main contractor; Freyssinet UK, the repair subcontractor and Technology Centre (formerly Taylor Woodrow Technology Centre), in charge of structural condition surveys.

\section{REFERENCES}

Anon (1878) The Victoria Dock extension. Engineering: an Illustrated Weekly Journal, 29 March, pp. 246-247.

BSI (2005) BS EN 1996-1-1:2005+A1:2012: Eurocode 6. Design of masonry structures. General rules for reinforced and unreinforced masonry structures. BSI, London, UK.

BSI (2007) BS EN 13791:2007: Assessment of in-situ compressive strength in structures and pre-cast concrete components. BSI, London, UK
Burland JB (1995) Assessment of risk of damage to buildings due to tunnelling and excavation. In Proceedings of First International Conference on Earthquake Geotechnical Engineering: IS-Tokyo, 14-16 November 1995 (Ishihara K (ed.)). Balkema, Rotterdam, the Netherlands, pp. 1189-1202.

Crossrail Act of 2008. Chapter 18. Her Majesty's Stationery Office, London, UK.

Glover DE, Newton E, Dale HM and Brown TR (1959) Port of London Authority: development of two dock areas, 1959. Proceedings of the Institution of Civil Engineers 15(4): 411-434, https://doi.org/10.1680/ iicep.1960.11823.

Liddell RR (1939) Improvements at the Royal Docks, Port of London Authority. Journal of the Institution of Civil Engineers 10(3): 283-310, https://doi.org/10.1680/ijoti.1939.14543.

LUL (London Underground Limited) (2010) 1-051: Civil engineering bridge structures. LUL, London, UK.

Mair RJ, Taylor RN and Burland JB (1996) Prediction of ground movements and assessment of risk of building damage due to bored tunnelling. In Proceedings of the International Symposium on Geotechnical Aspects of Underground Construction in Soft Ground: London, UK, 15-17 April 1996 (Mair RJ and Taylor RN (eds)). Balkema, Rotterdam, the Netherlands, pp. 713-718.

McKibbins L, Elmer R and Roberts K (2010) Tunnels: Inspection, Assessment and Maintenance. Construction Industry Research and Information Association, London, UK, C671.

Network Rail (2009a) Technical User Manual for the Application of Standard Tunnel Repairs. Network Rail, London, UK, NR/CIV/TUM/ 520 .

Network Rail (2009b) Tunnel Lining Maintenance Repair - Standard Drawings. Network Rail, London, UK, NR/CIV/SD/520-NR/CIV/SD/ 541.

Network Rail (2009c) Examination of Structures Record of Tunnel Examinations. Network Rail, London, UK, NR/L3/CIV/0006/4C.

Wilde D and Craft JR (2015) Rehabilitation of a Victorian Railway tunnel for Crossrail. In Crossrail Project: Infrastructure Design and Construction (Black M, Dodge C and Yu J (eds)). Thomas Telford, London, UK, vol. 2, pp. 251-264.

Wilde D and Craft JR (2016) Rehabilitation of the Victorian Connaught Tunnel for London's Crossrail project - design challenges. The Structural Engineer, August: pp. 24-32.

\section{How can you contribute?}

To discuss this paper, please email up to 500 words to the editor at journals@ice.org.uk. Your contribution will be forwarded to the author(s) for a reply and, if considered appropriate by the editorial board, it will be published as discussion in a future issue of the journal.

Proceedings journals rely entirely on contributions from the civil engineering profession (and allied disciplines). Information about how to submit your paper online is available at www.icevirtuallibrary.com/page/authors, where you will also find detailed author guidelines. 